\title{
Laser welding of current collector foil stacks in battery production-mechanical properties of joints welded with a green high-power disk laser
}

\author{
Sophie Grabmann ${ }^{1}$ (D) . Johannes Kriegler ${ }^{1}$ (D) . Felix Harst ${ }^{1}$ (D) . Florian J. Günter ${ }^{1}$ (D) . Michael F. Zaeh ${ }^{1}$
}

Received: 20 May 2021 / Accepted: 2 August 2021 / Published online: 1 October 2021

(C) The Author(s) 2021

\begin{abstract}
The qualification of production systems that enable reliable and stable production processes is a major challenge in manufacturing large-format lithium-ion batteries. During cell assembly, the electrode sheets of the anode and the cathode are stacked, and are electrically contacted by a welding process. It was shown that laser beam welding employing a beam source in the green wavelength range is a promising joining approach in terms of high productivity. Therefore, the influence of the process parameters, such as the laser power, the welding speed, the pulse frequency, and the pulse duration, on the weld seam quality was investigated. Particular emphasis was placed on the mechanical strength of the weld seam. Statistically planned experiments were used to determine feasible parameter sets for welding the most common current collectors of lithium-ion battery electrodes, copper $(\mathrm{Cu})$, and aluminum $(\mathrm{Al})$. The influence of the individual process parameters on the tensile shear force was evaluated. Stacks of 40 metal foils were welded with a thin metal sheet in lap joint configuration. Based on an analysis of the requirements for minimum mechanical seam strengths, this study confirms that laser beam welding using a green high-power disk source is an auspicious process for the internal contacting of lithium-ion batteries.
\end{abstract}

Keywords Laser beam welding · Green high-power disk laser · Lithium-ion batteries · Mechanical seam properties · Micro welding

\section{Introduction}

As a result of the transition to renewable energies, the demand for electrical energy storage systems is continuously increasing. Due to their high energy and power densities, lithium-ion batteries (LIBs) are used in many applications, e.g., portable electronics, power tools, and electric vehicles (EVs) [1], as preferential battery technology [2]. LIBs are made of multiple electrochemical elementary cells composed of an anode and a cathode, which are electrically isolated by a separator layer [3]. The process chain for manufacturing LIBs consists of a large number of process steps. In the electrode production, electrochemically active materials are mixed with conductive additives as well as binding agents [4]

Sophie Grabmann

sophie.grabmann@iwb.tum.de

1 Institute for Machine Tools and Industrial Management (iwb), Boltzmannstrasse 15, 85748 Garching, Germany and are coated on metallic current collectors to form porous electrode layers [5]. Due to different electrochemical potentials at the two electrodes, copper and aluminum foils are used on the anode and cathode sides as current collectors [6]. Low foil thicknesses (copper thickness: 6-12 $\mu \mathrm{m}$, aluminum thickness $12-20 \mu \mathrm{m}$ ) are targeted to reduce the proportion of passive components, thus materials that do not contribute to the energy content of the LIBs [7]. For the production of LIBs, the electrode materials are calendered to adjust the porosity [8]. Subsequently, anodes and cathodes are cut out of the electrode coils [9] and are stacked or winded with separator layers [10]. Afterwards, the electrode sheets are mechanically and electrically conductively connected during the cell internal contacting process [11]. For this purpose, the individual uncoated current collector flags of the anodes and the cathodes are welded together and joined to an arrester tab. The tab is used to ensure the electrical current flow from the electrode stack during operation. The cells are finalized by packaging the stacks in a hard-case or pouch cell housing. The cells are filled with liquid electrolyte and the layers 
are wetted to ensure ionic conductivity [12]. After sealing the housing, the LIBs are electrochemically conditioned and are then ready for operation. During cell lifetime, the mechanical integrity of the weld seams connecting the individual collector foils must be maintained as the total requested power is conducted through the joints. The weld seams are subject to high-quality requirements, in particular, low electrical resistance and high mechanical strength [13]. Thus, a joining process exhibiting high reliability, e.g., avoiding weld spatter, is demanded.

Therefore, a profound understanding of the welding process is necessary. Previous research has shown that laser beam welding (LBW) is a promising joining method for cell internal contacting.

\section{State of the art}

Commonly, ultrasonic welding (USW) is used for joining the electrode current collectors [14]. The workpieces are clamped between a sonotrode and an anvil, applying a transversal ultrasonic vibration and a joining pressure [15]. This solid-state welding process is limited with regard to the process stability. High-frequency oscillations are introduced into the electrode sheets, which can mechanically damage the joining partners due to excessive welding energies [16]. Especially thin layers [17] are susceptible to defects, e.g., by cracking or substantial deformation. Besides transverse vibration, excitation of the components was reported to cause structural damage to the cell components [18]. Detaching particles pose a danger of short-circuits within the cell during cell operation [19]. Furthermore, progressing tool wear and poor weld tool alignment can affect the weld quality [20]. The need for accessibility to the joint from two sides is a limiting factor for the cell and the process design.

LBW, a contactless joining process, is a promising alternative alleviating the limitations of USW. Beam deflection using galvanometric scanning optics allows for a welding process with high geometric flexibility and scanning speeds of more than $5 \mathrm{~ms}^{-1}$ [21].

Using an overlap joint with a maximum number of joining partners of $n=2$, basic investigations on LBW of metallic foils were carried out [22, 23]. Due to the low thickness $(<100 \mu \mathrm{m})$ of the individual joining partners, the process is classified as micro-welding [24]. In comparison to macro-welding tasks, other boundary conditions apply due to the high surface-to-volume ratio. For example, thermal distortions by scaled energy input per unit length increase exponentially with decreasing material thicknesses [25] and cause a change in the gap distance of the joining partners. Therefore, the clamping technique is essential for a stable welding process [23].
Regarding the application of LBW for cell internal contacting, different infrared (IR) laser systems and joint configurations were investigated [26]. The most promising seam properties were achieved with an overlap configuration of the joining partners and a single-mode laser system. The better results in comparison to a multi-mode laser system were attributed to the smaller focus diameter, and thus, the higher energy density of the single-mode laser system. The use of support sheets on the top and the bottom of the stack prevented damage to the thin foils. However, in some cases, the seams showed a strong surface roughness. To prevent the detachment of these seam irregularities, a time-consuming smoothing of the weld after joining was necessary [26].

The mechanical loads applied to the joining components during USW were reduced using LBW [27]. Besides the multitude of surface layers between the joining partners, e.g., oxide layers, the air entrapped between the foils posed a major challenge. It remained as pores in the seams. Thus, an increase in the number of foils led to an increased porosity within the weld seams. A reduction of the welding speed caused larger pores and higher overall porosity [27].

With a beam oscillation process strategy applying IR laser radiation, the joining of copper foil stacks with up to $n=30$ layers and layer thicknesses of $d=17-100 \mu \mathrm{m}$ was enabled. Due to the low absorptivity of copper for IR laser radiation, the workpieces were brushed before joining to minimize back reflection of the laser radiation to improve the coupling of the beam. Aluminum foils with a thickness of $100 \mu \mathrm{m}$ were joined successfully, while foils with a thickness of $20 \mu \mathrm{m}$ were detached from the weld seam in the area of the heat-affected zone (HAZ) [28].

For the application of LBW in LIB production, it is important to avoid thermal damage to the temperaturesensitive cell components during joining. Another risk is posed by possible short circuits caused by particles or damage to the separator. Commonly used separators are made of polypropylene and have a melting temperature $T_{\mathrm{m}}$ of around $135^{\circ} \mathrm{C}$ [29]. If this temperature is exceeded, the pores of the separator can clog and block the ion transport within the cell [29]. A widely applied electrode binder (polyvinylidenfluoride (PVDF)) has a melting temperature $T_{\mathrm{m}}$ of around $170^{\circ} \mathrm{C}$. Melting of the binder can cause the mechanical integrity of the electrode to be lost and particles to be detached. The heat input was significantly reduced during the LBW of copper foil stacks $(n=15)$ using millisecond spike pulses [30].

Different approaches are currently being discussed to further improve foil welding. Modern high-power laser beam sources in the visible wavelength range (400-780 nm) open up new opportunities for increasing the process reliability of cell internal contacting $[11,31]$. 
The absorption coefficient of copper materials at room temperature for green radiation is about seven times higher compared to IR radiation. Weld spatter and melt pool instabilities, which can occur in material processing with IR radiation, were therefore significantly reduced [32].

The copper material was melted at lower intensities regardless of the surface condition with green laser radiation [33]. The resulting weld seams without melt ejections were characterized by an exceptionally high surface quality [34]. Similar observations were made using a blue laser radiation for welding copper materials $[35,36]$.

Using a green laser radiation, 30 foils were successfully joined in an overlap configuration [11]. Based on the evaluation of cross sections, it was shown that 20 layers of $8 \mu \mathrm{m}$ thick copper foils can be welded in a overlap configuration using a blue laser radiation [35]. However, the process speeds are limited. In a further study, the maximum joinable number of copper foils was investigated (thickness: $8 \mu \mathrm{m}$ and $10 \mu \mathrm{m})$. With an increasing number of foils, the welding speed had to be reduced successively. Up to 40 foils were joined in a lap joint configuration at a low process speed of $0.5 \mathrm{~m} \mathrm{~min}^{-1}$ [36].

The described studies proved the basic suitability of using green and blue laser radiation for welding foil stacks. Comparing the blue laser radiation source to the green laser radiation shows that the process speeds are significantly reduced using the blue laser radiation. However, the mechanical and electrical properties of the corresponding joints have not yet been investigated in detail. Furthermore, the effects of process parameters on the seam quality were not examined so far.

\section{Objective and approach}

Within this work, LBW as a process for cell internal contacting in LIB production was investigated. As stateof-the-art substrates for LIB anodes and cathodes, copper and aluminum foils were used for the experiments. The relationship between the process parameters and the resulting weld seam properties was examined. Special focus was placed on the mechanical properties of the weld seams since the detachment of foils in battery operation, e.g., due to shocks and vibration, leads to electrical contact loss and battery failure. A millisecond rectangular pulse welding strategy with a beam source emitting in the green wavelength range was used for the micro-welding process. First, suitable parameter windows were determined. Based on that, statistically planned experiments were performed to investigate the influence of the individual process parameters, the laser power, the welding speed, the pulse duration, and the pulse frequency. The tensile shear force $F$ was selected as a quality measure and was quantified.
Last, the determined strengths were evaluated with regard to the requirements for cell operation based on calculated minimum tensile forces $F_{\text {min }}$. For this purpose, different cell sizes with commercially common capacities and standard test specifications were used.

\section{Experimental set-up}

\subsection{Laser system and welding set-up}

The investigations were carried out using a disk laser emitting at a wavelength of $\lambda=515 \mathrm{~nm}$ with a maximum laser power of $P_{\max }=1 \mathrm{~kW}$. The characteristics of the laser system are summarized in the Appendix (see Table 3). The minimum adjustable pulse duration $t_{\mathrm{p}}$ for the selected laser system is $0.3 \mathrm{~ms}$. To ensure a pulse welding process, the product of the pulse frequency $f$ and the pulse duration $t_{\mathrm{p}}$ must be below 1 . In terms of technical feasibility, the product of the pulse frequency and the pulse duration was kept below 0.7 in the experiments. The laser beam was focused on the uppermost foil using a galvanometric scanning system. To ensure a gap-free welding configuration of the foil stacks, a clamping device as depicted in Fig. 1 was employed. To account for the production of large-format LIBs, an application-oriented welding task consisting of 40 metal foils and an arrester tab in a lap joint configuration was evaluated. Battery-grade copper (Cu-PHC, Schlenk $A G$, Germany) and aluminum (EN AW-1050A, Korff AG, Switzerland) foils with thicknesses of $10 \mu \mathrm{m}$ and $15 \mu \mathrm{m}$ respectively were connected to a $300 \mu \mathrm{m}$ thick arrester tab (Cu-OF, Gemmel GmbH, Germany, and EN AW-1050A, Bikar GmbH, Germany). The dimensions and the materials of the test samples are specified in Table 1. To enable clamping for tensile testings, a rectangular geometry of $60 \mathrm{~mm} \times 25 \mathrm{~mm}$ was selected for the joining partners. The overlap between the foil stack and the tab was $l_{\mathrm{u}}=$ $12.5 \mathrm{~mm}$. Each weld seam was $20 \mathrm{~mm}$ long and placed in the center of the overlap area as depicted in Fig. 1.

\subsection{Method for the welding experiments}

For the welding tests, millisecond laser pulses with a quasirectangular temporal pulse shape were used. The welding strategies were characterized by the laser power $P$, the welding speed $v$, the pulse duration $t_{\mathrm{p}}$, and the pulse frequency $f$. Experiments with two fixed and two varied parameters each were conducted to define a parameter window. For the copper samples, the laser power and the welding speed were varied in steps of $100 \mathrm{~W}$ and $2.5 \mathrm{mms}^{-1}$, respectively. To account for industrially relevant processing times, the minimum welding speed was set to 


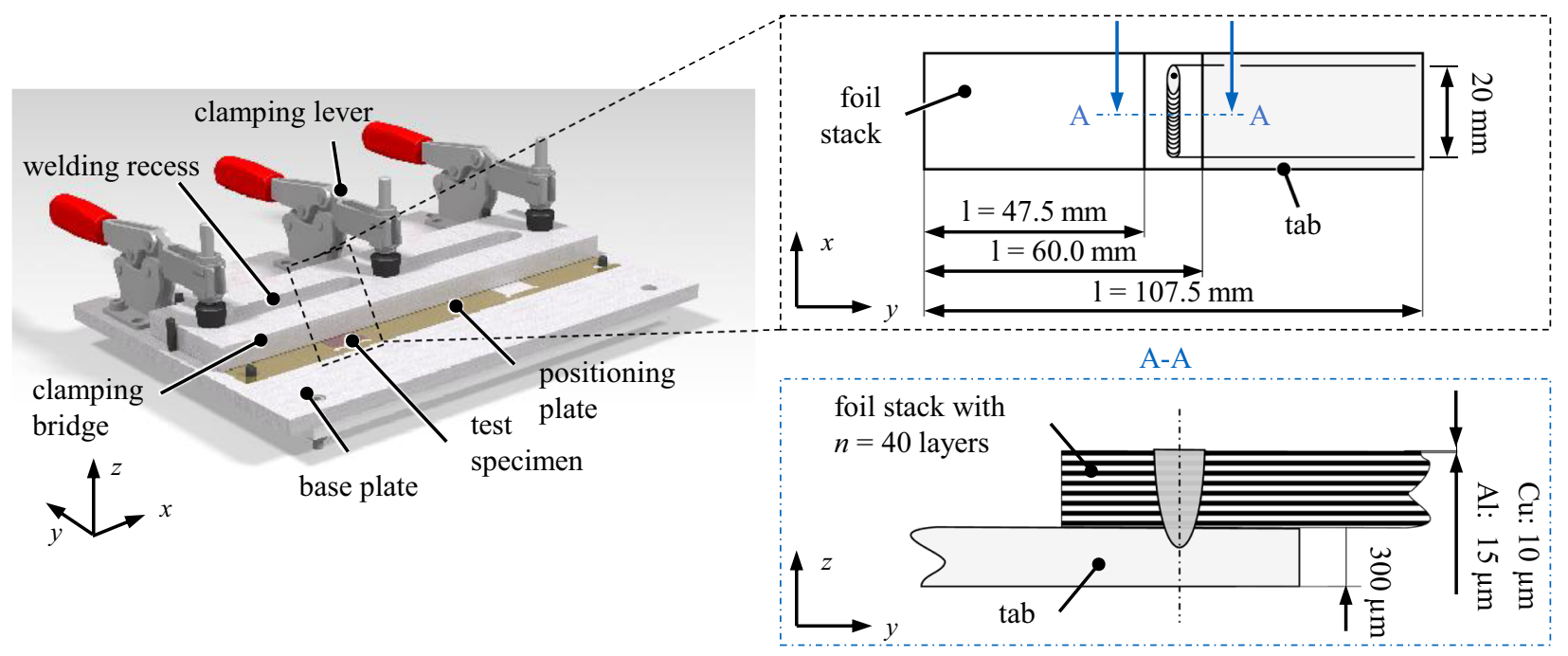

Fig. 1 Schematic drawing of the experimental set-up (left) and the test specimen geometry (right)

$v=5.0 \mathrm{mms}^{-1}$. The pulse frequency was examined in steps of $50 \mathrm{~Hz}$ starting at $f=100 \mathrm{~Hz}$. The influence of the pulse duration was evaluated for values between $1 \mathrm{~ms}$ and $3 \mathrm{~ms}$. For aluminum, the frequency and the pulse duration ranges were chosen identically to the ranges used for copper, as these covered a wide spectrum of the technically feasible parameter room. The parameter ranges for the power and the welding speed were adjusted. The melting point of aluminum $\left(T_{\mathrm{m}}=660^{\circ} \mathrm{C}\right.$ [37]) is significantly lower than that of copper $\left(T_{\mathrm{m}}=1084^{\circ} \mathrm{C}[37]\right)$.

Thus, lower power levels and higher welding speeds were selected for aluminum. A welding speed of $v=$ $8 \mathrm{mms}^{-1}$ was chosen as the lower limit and was varied in steps of $4 \mathrm{mms}^{-1}$ with regard to the later orthogonal experimental design. The laser power was investigated in steps of $100 \mathrm{~W}$ starting at $P=650 \mathrm{~W}$. The obtained weld seams were evaluated by visual inspection. The parameter sets of optically promising seams (see Section 4.3) were subsequently used to produce welds, using a central composite experimental design (CCD), to characterize the tensile shear force $F$. Each experimental design factor was examined on five levels, resulting in 25 individual parameter sets per block. A factor distance $\alpha=1.4$ was chosen to ensure an orthogonal design. The normalized factor values were $-1.4,-1.0,0,+1.0$, and +1.4 . The natural values of the factor levels for the tensile shear force tests were determined based on the optically inspected weld seams, see
Section 4.3. Parameter combinations which were classified as under weld or over weld were excluded. The factor levels 0 of each parameter were placed in the middle of the identified parameter window (see Fig. 4 in Section 5), which were $P=850 \mathrm{~W}, v=7.5 \mathrm{mms}^{-1}, f=175.0 \mathrm{~Hz}$, and $t_{\mathrm{p}}=2.5 \mathrm{~ms}$ for copper. The respective factor levels 0 for aluminum were $P=875 \mathrm{~W}, v=12.0 \mathrm{mms}^{-1}$, $f=225.0 \mathrm{~Hz}$, and $t_{\mathrm{p}}=2.5 \mathrm{~ms}$. Subsequently, the values for the factor levels 1.0 and -1.0 of the respective parameters were selected. The difference between the parameter values at level 0 and level -1.0 is equal to the difference between the parameter values at level 1.0 and 0 [38]. Stages 1.0 and -1.0 were set to the largest possible range of parameter values to achieve welds classified as good, see Fig. 4. Levels -1.4 and +1.4 were intended to cover the outer margins of the parameter range to reduce possible misclassifications. Table 2 lists a summary of the absolute parameter settings for each factor. The complete test plans are summerized in the Appendix in Table 5 for copper and in the Appendix in Table 6 for aluminum. Three welds were produced for each parameter set.

\subsection{Seam analysis}

Visual inspection The welds were categorized into three groups by a visual inspection of the foil stacks from the top view, the arrester tabs from the bottom view, and

Table 1 Overview of the used welding geometries and the used materials

\begin{tabular}{lllllll}
\hline Test series & Dimension of the tab & Material of the tab & Dimension of the foil & Material of the foil & $\begin{array}{c}\text { Number of foils } \\
\text { in the stack } n\end{array}$ & $\begin{array}{c}\text { Weld } \\
\text { length } l_{\mathrm{w}}\end{array}$ \\
\hline $\mathrm{Cu}$ & $60.0 \times 25.0 \times 0.3 \mathrm{~mm}$ & Cu-OF & $60.0 \times 25.0 \times 0.010 \mathrm{~mm}$ & Cu-PHC & 40 & $20.0 \mathrm{~mm}$ \\
$\mathrm{Al}$ & $60.0 \times 25.0 \times 0.3 \mathrm{~mm}$ & EN AW-1050A & $60.0 \times 25.0 \times 0.015 \mathrm{~mm}$ & EN AW-1050A & 40 & $20.0 \mathrm{~mm}$
\end{tabular}


Table 2 Summary of the chosen parameter levels for each investigated parameter

\begin{tabular}{llll}
\hline Test series & Input value & & Setting range* \\
\hline $\mathrm{Cu}$ & Power & $P$ & $780 \mathrm{~W}, 800 \mathrm{~W}, 850 \mathrm{~W}, 900 \mathrm{~W}, 921 \mathrm{~W}$ \\
& Welding speed & $v$ & $4.0 \mathrm{mms}^{-1}, 5.0 \mathrm{mms}^{-1}, 7.5 \mathrm{mms}^{-1}, 10.0 \mathrm{mms}^{-1}, 11.0 \mathrm{mms}^{-1}$ \\
& Pulse duration & $t_{\mathrm{p}}$ & $1.8 \mathrm{~ms}, 2.0 \mathrm{~ms}, 2.5 \mathrm{~ms}, 3.0 \mathrm{~ms}, 3.2 \mathrm{~ms}$ \\
& Pulse frequency & $f_{\mathrm{p}}$ & $139.8 \mathrm{~Hz}, 150.0 \mathrm{~Hz}, 175.0 \mathrm{~Hz}, 200.0 \mathrm{~Hz}, 210.3 \mathrm{~Hz}$ \\
$\mathrm{Al}$ & $P$ & $805 \mathrm{~W}, 825 \mathrm{~W}, 875 \mathrm{~W}, 925 \mathrm{~W}, 946 \mathrm{~W}$ \\
& Power & $v$ & $6.4 \mathrm{mms}, 1.0 \mathrm{mms}-1,12.0 \mathrm{mms}^{-1}, 16.0 \mathrm{mms}^{-1}, 17.6 \mathrm{mms}^{-1}$ \\
& Welding speed & $t_{\mathrm{p}}$ & $1.8 \mathrm{~ms}, 2 \mathrm{~ms}, 2.5 \mathrm{~ms}, 3.0 \mathrm{~ms}, 3.21 \mathrm{~ms}$ \\
& Pulse duration & $f_{\mathrm{p}}$ & $189.8 \mathrm{~Hz}, 200.0 \mathrm{~Hz}, 225.0 \mathrm{~Hz}, 250.0 \mathrm{~Hz}, 260.3 \mathrm{~Hz}$ \\
\hline
\end{tabular}

*Values correspond to normalized factor values of $-1.4,-1.0,0,+1.0$, and +1.4

metallographic cross-sections of the weld. A weld was classified as under weld, when no complete bonding of the foils and the tab was achieved. Welds showing burns and visible heat penetration on the backside of the tab were assigned to the over weld group. The welded seams were also marked as over weld, if there were strong traces of carbon accumulation on the top of the seam. Welding carbonization must be avoided, as contaminating particles may be introduced into the cell. If none of these errors occurred, the welds were graded as good weld. In Fig. 2 the classification is shown by the example of the three weld types.

Cross-sections For the metallographic analysis, the seams were cold embedded in epoxy resin to prevent a change of the seam properties and thus to enable a high degree of detection of all seam irregularities. The specimens were ground in three steps to the seam center $(280,600,1200$ grit) and then polished $(3 \mu \mathrm{m}, 1 \mu \mathrm{m}$, and oxide final polishing suspension (OPS)). As the last preparation step, the copper specimens were treated with an etchant with medium acidity (Klemm II) to prevent damage to the sensitive foils. The aluminum specimens were etched with Kroll reagent. Images of the cross-sections were taken on a reflected light microscope (MM40, Nikon, Japan).
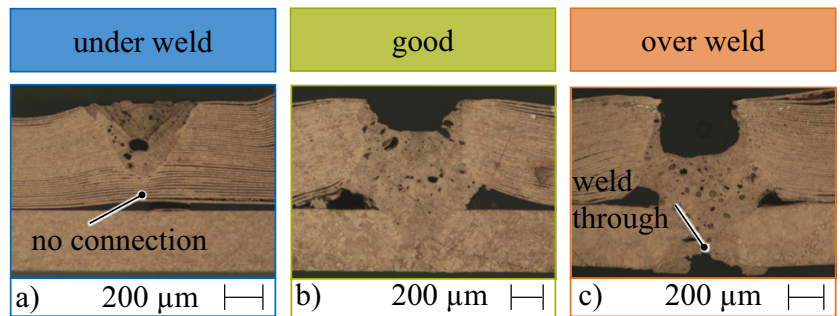

Fig. 2 Chosen categories for the classification of the weld seams using examples of the welded copper specimens: under weld (a), good weld (b), over weld (c)
Seam strength analysis The tensile shear forces of the seams were examined using lap shear tests. The tests were performed following DIN EN 1465 and DIN EN ISO 5273 as there is no standardized testing method for foil stacks. The geometry of the specimens was chosen according to DIN EN 1465, a standard for lap shear testing of adhesive bondings. For metals there is no testing standard for lap joints. The tests were carried out on a tensile testing machine (XForce K, Zwick Roell, Germany) with a $1 \mathrm{kN}$ load cell. The selected testing set-up is shown in Fig. 3. The upper and lower clamping jaws were offset by the thickness of the tab in order to prevent forces transverse

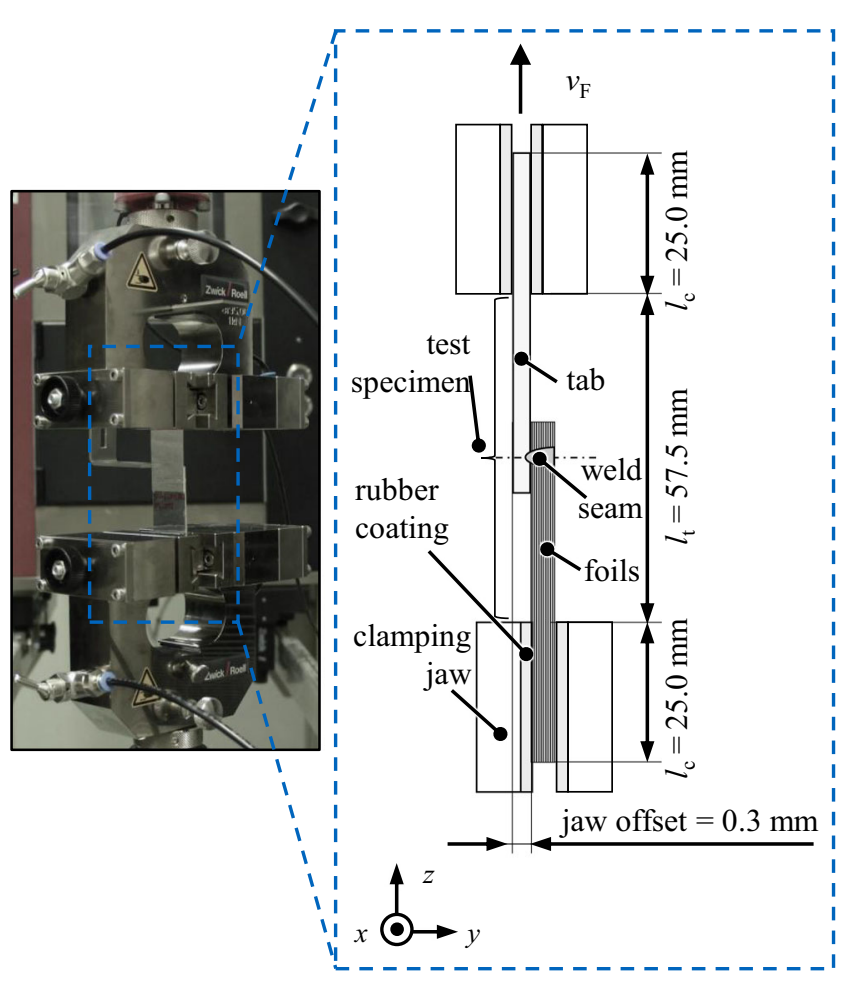

Fig. 3 Photograph of the clamping device with a mounted specimen (left) and schematic drawing of the tensile test set-up (right) 
to the direction of tension ( $z$-axis). After applying a preload of $1 \mathrm{~N}$ to compensate for clamping forces and to ensure a complete extension of the foils, the tensile test was performed at a feed rate of $v_{\mathrm{t}}=50 \mathrm{~mm} \mathrm{~min}{ }^{-1}$, according to DIN EN ISO 527-3 a standard for tensile testing of single foils. Exemplary test curves of lap shear tests for the copper samples with and without applying a pre-load are shown in the Appendix (see Fig. 10). For evaluating the mechanical strength of the seams, the tensile shear forces $F$ were compared. In Section 5.4, a method is presented to calculate the required minimum tensile forces $F_{\min }$ with regard to cell operations. After specimen failure, the fracture pattern was documented to conclude whether the weld seams or the bulk materials failed. The test parameters used for the tensile tests are summarized in Table 4. In addition, tensile tests according to DIN EN ISO 527-3 were performed on single copper $(25 \times 60 \times 0.01 \mathrm{~mm})$ and aluminum foils $(25 \times 60 \times 0.15 \mathrm{~mm})$ with the same geometry and clamping as used for the foil stacks for material characterization. These tests were performed 25 times each. The average tensile strength $R_{\mathrm{m}}=\frac{F}{A}$ of one copper foil was $R_{\mathrm{m}}=$ $367 \mathrm{MPa} \pm 38.8 \mathrm{MPa}$ and that of one aluminum foil was $R_{\mathrm{m}}=91 \mathrm{MPa} \pm 1.6 \mathrm{MPa}$.

\section{Results and discussion}

\subsection{Determination of a parameter window}

The results of the experiments to identify a suitable parameter window are shown in Fig. 4.
First, the process window was narrowed down concerning both the laser power and the welding speed (see Fig. 4a). The frequency and the pulse duration were kept constant at $f=200 \mathrm{~Hz}$ and $t_{p}=2 \mathrm{~ms}$. At a laser power of $P=700 \mathrm{~W}$, no sufficient bonding was achieved for any welding speed ranging from $v=5.0 \mathrm{mms}^{-1}$ to $12.5 \mathrm{mms}^{-1}$ for copper. With a laser power of $P=1000 \mathrm{~W}$, the weld seams were classified as good welds for $v \geq 10 \mathrm{mms}^{-1}$. At lower welding speeds, the increased heat input led to a burning of the upper copper foils. For welding the aluminium specimens (see Fig. 4d), under welds were observed for a laser power of $P=650 \mathrm{~W}$ at all investigated welding speeds, as well as for a laser power of $P=750 \mathrm{~W}$ at welding speeds of $v=16 \mathrm{mms}^{-1}$ to $20 \mathrm{mms}^{-1}$. Optically promising weld seams (good welds) were achieved for all other investigated variations of the laser power and the welding speed. In general, for both copper and aluminum, the bonding decreased continuously with increasing welding speed $v$, which is referred to the reduction of the applied energy input per unit length.

At low frequencies, under welds were found for both materials (see Fig. 4b and e). Due to the bad connection for $f=100 \mathrm{~Hz}$, this frequency was excluded for further tests. Using pulse frequencies of $f=250 \mathrm{~Hz}$ and higher led to over weld seams for copper. At a pulse frequency of $f=300 \mathrm{~Hz}$ an over weld was found for aluminum. Overall, increasing the pulse frequency implies linearly increased welding energies. If the laser power is additionally increased, the energy input per unit length increases quadratically. Therefore, over welds were found for high frequencies and high laser powers.

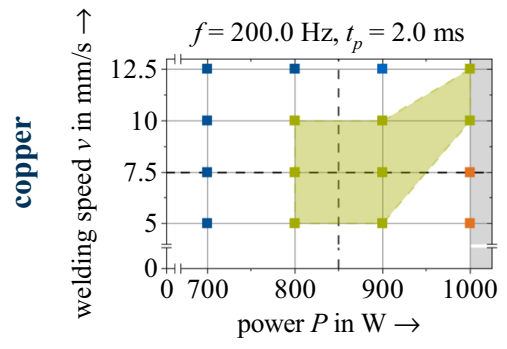

a)

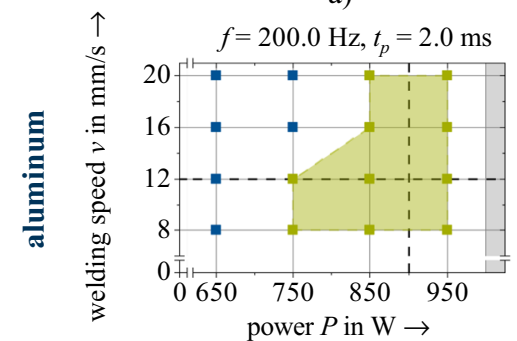

d)

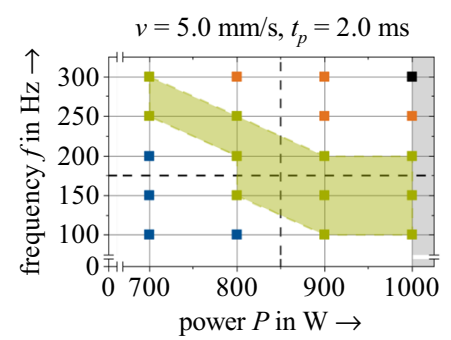

b)

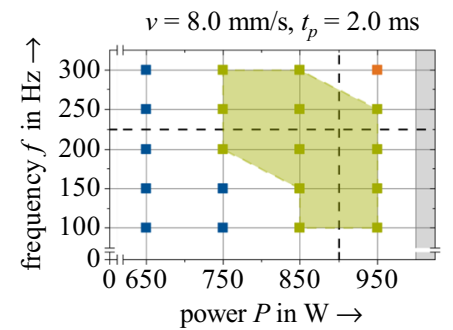

e)

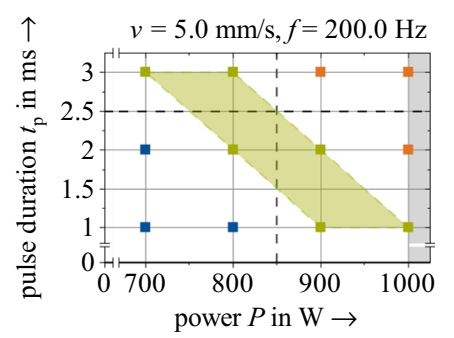

c)

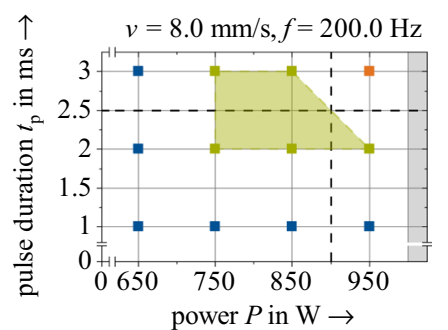

f)

- under weld | good weld - over weld - technically not feasible - - -parameter window — power limit --- -factor level $0 \|$ axis break

Fig. 4 Identified process regimes and parameter windows for contacting copper $(\mathrm{a}-\mathrm{c})$ and aluminum (d-f) foils with an arrester tab using a millisecond welding strategy with two varied and two fixed input parameters. The values of the two fixed input parameters are given on top of the respective diagrams 
At a pulse duration of $t_{\mathrm{p}}=1 \mathrm{~ms}$, good welds were achieved at $P \geq 900 \mathrm{~W}$ (see Fig. 4c) for welding the copper foils. Figure $4 \mathrm{f}$ shows that all aluminium welds were classified as under weld at a pulse duration of $t_{\mathrm{p}}=1 \mathrm{~ms}$. As longer pulse durations lead to a longer interaction time between the laser pulse and the material, more heat is transferred to the workpiece. Thus, good welds were obtained for either low powers and high pulse durations or high powers and low pulse durations. Combinations of high pulse durations and high laser powers led to over welds, while low laser powers together with low pulse durations led to under welds.

\subsection{Influences of individual parameters on the tensile shear force}

Based on the identified parameter windows, the influence of the individual factors and possible interactions with regard to the tensile shear force were investigated. Figure 5 shows the main effect diagrams with the corresponding confidence intervals for each main factor for copper and aluminum. The factor diagrams are based on a multivariate linear regression model. The abscissa is subdivided according to the used factor levels.

For copper, the mechanical strength increased with the factors laser power $P$, frequency $f$, and pulse duration $t_{\mathrm{p}}$. An increase of the welding speed $v$ was followed by a decrease in the tensile shear force. Comparing the slope of the individual effect curves shows that the pulse duration had the most and the welding speed the least decisive influence on the tensile shear force. The effect diagrams of the aluminum samples show similar trends compared to the graphs of copper. The factors welding power $P$, frequency $f$, and pulse duration $t_{\mathrm{p}}$ had a positive effect on the tensile shear force, while an increase in the welding speed $v$ led to a reduction of the mechanical strength. Compared to copper, the confidence intervals were smaller, attributed to the overall lower scatter of the measured tensile shear forces for aluminum. In Section 5.3, this is discussed in more detail. In a direct comparison of the two materials, it must be taken into account that the leverage for increasing the tensile shear forces by adjusting the investigated factors is significantly lower in the case of aluminum.

\subsection{Characteristics of the mechanical strengths}

In Fig. 6 the determined tensile shear forces are shown as a function of the energy input per unit length $E_{1}=P \cdot t_{\mathrm{p}} \cdot f$. $v^{-1}$.

Some parameter sets of the experimental plans correspond to the same energy input per unit length $E_{1}$. Each parameter set is included as a separate data point in Fig. 6. Overall, the tensile shear force increased with the energy input per unit length. For lower line energies, tensile shear forces below $200 \mathrm{~N}$ were found for copper. Besides that,

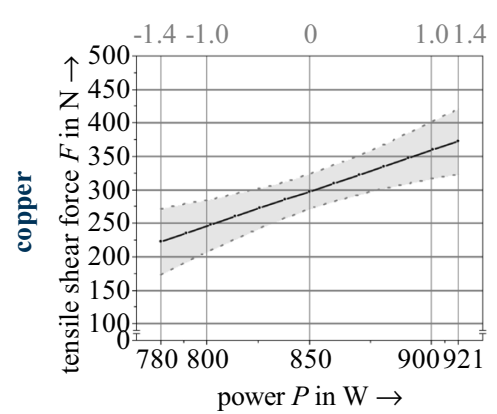

a)

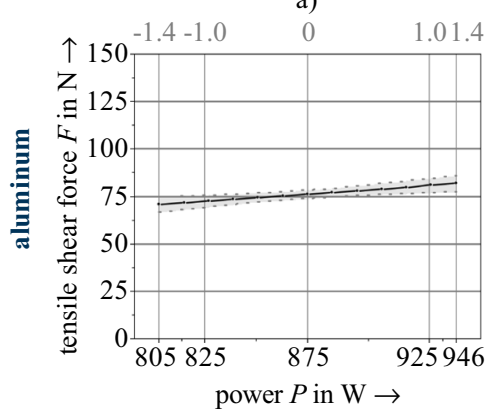

e)

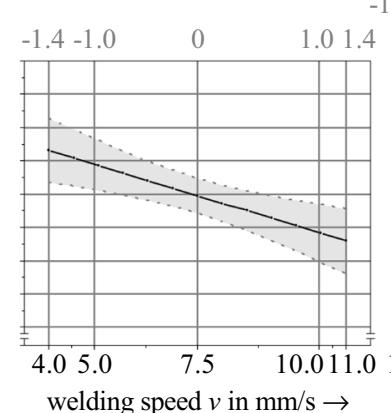

b)

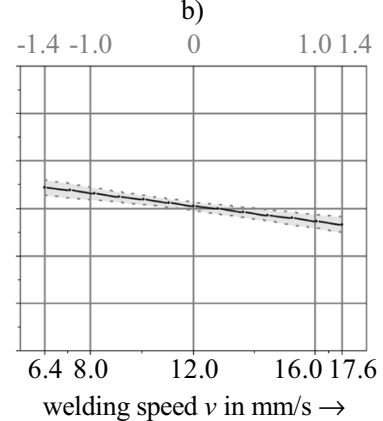

f)
-1.4 to 1.4 : normalized factor values

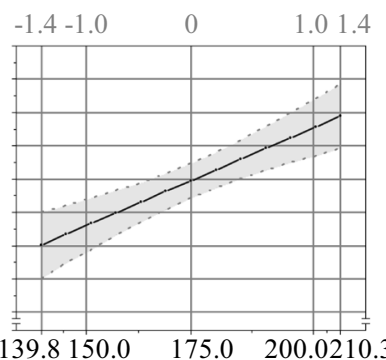

frequency $f$ in $\mathrm{Hz} \rightarrow$

c)

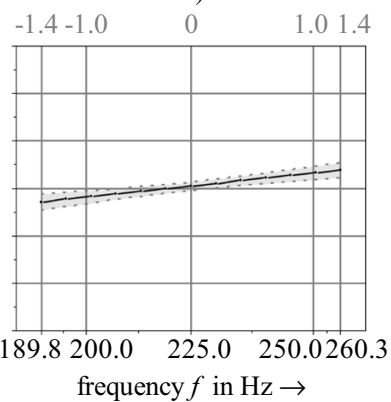

g)

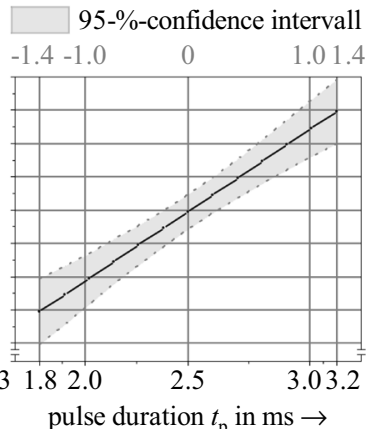

d)

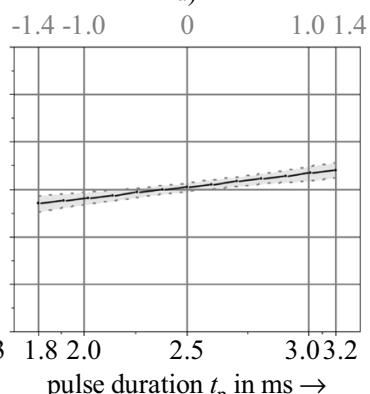

h)

Fig. 5 Main effects of the process parameters on the target value tensile shear force $F$ for the material copper $(\mathrm{a}-\mathrm{d})$ and for the material aluminum $(\mathrm{e}-\mathrm{h})$. The parameter values on the abscissae are scaled

based on the set factor levels of the CCD testing plan and correspond to the normalized factor levels from -1.4 to 1.4 
- mean value Istandard deviation 1 number of the parameter set with equal $E_{1}$

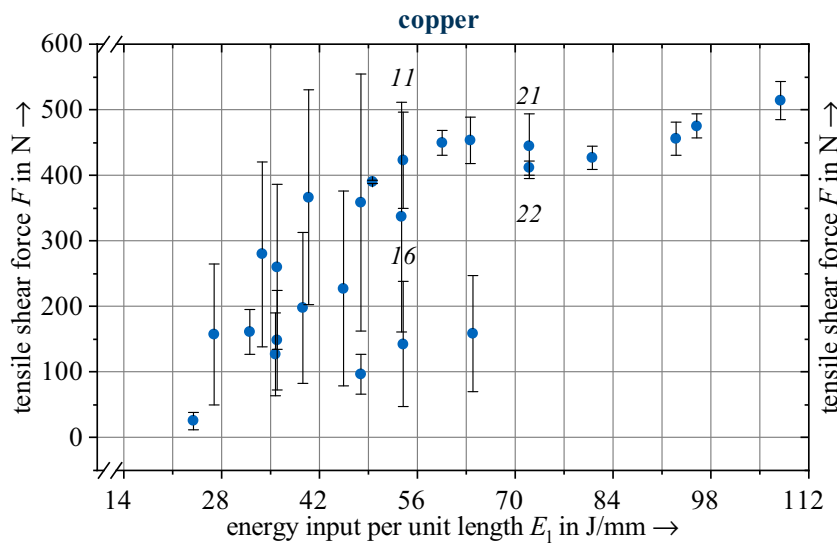

a)

Fig. 6 Mean values of the measured tensile shear forces $F$ over the energy input per unit length $E_{1}$ for the copper samples (a) and the aluminum samples (b); the individual data points at one energy input

the measured tensile shear forces scattered more at lower line energies. With increasing energy input per unit length $E_{1}$, the tensile shear force converged towards $500 \mathrm{~N}$ for the copper and $100 \mathrm{~N}$ for the aluminum specimens. The standard deviation decreased significantly with an increasing energy input per unit length.

The maximum tensile shear force was $514 \mathrm{~N}$ at an energy input per unit length of $108 \mathrm{~J} \mathrm{~mm}^{-1}(P=900 \mathrm{~W}$, $v=5 \mathrm{mms}^{-1}, f=200 \mathrm{~Hz}, t_{\mathrm{p}}=3 \mathrm{~ms}$ ) for the copper specimens and $92 \mathrm{~N}$ for the aluminum specimens. The respective energy input per unit length was $87 \mathrm{~J} \mathrm{~mm}^{-1}$ $\left(P=925 \mathrm{~W}, v=8 \mathrm{mms}^{-1}, f=250 \mathrm{~Hz}, t_{\mathrm{p}}=3 \mathrm{~ms}\right)$.

These observations correspond with the fracture patterns that occurred (see Fig. 7). Two fracture modes were found. On the one hand, the failure occurred directly in the weld seam, as shown in Fig. 7a. This fracture pattern indicates that the weld was the weak spot and was observed in the specimens with a low tensile shear force and a maximum energy input per unit length of $64 \mathrm{~J} \mathrm{~mm}^{-1}$ for copper and $30 \mathrm{~J} \mathrm{~mm}^{-1}$ for aluminum. The second failure pattern detected, as shown in Fig. 7b, was cracking adjacent to the weld. In general, the damage emerged from the HAZ.

More heat is introduced into the workpiece with an increasing energy input per unit length, which correlated with higher tensile shear forces. Regarding the cross sections of the weld seams, an increased bonding between the foils and the arrester tab was observed (see Fig. 8). From Fig. 8a-c and from cross Fig. 8d-f, the energy input per unit length and the measured tensile shear force increased. The cross sections for the copper and the aluminum specimens showed that the total welding depth increased with the increasing energy input. An increased penetration into the arrester tab correlated with higher mechanical seam

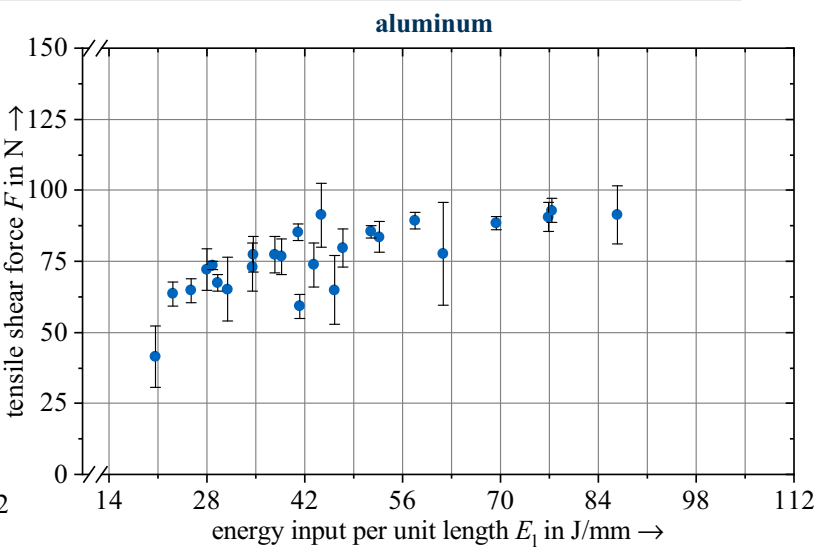

b)

per unit length correspond to different parameter sets of the CCD test plans (see Table 5 for copper and Table 6 for aluminum) with different combinations of the parameters

strength. DAS et al. made similar observations for welding steel foils [39].

At a low energy input per unit length, the lower range of the defined process window, in which a penetration into the tab can be achieved, is reached. Therefore, the welding depth and the weld seam width were small. Besides, the welding depth and the weld seam width were not constant over the entire seam length. As a result, significantly larger

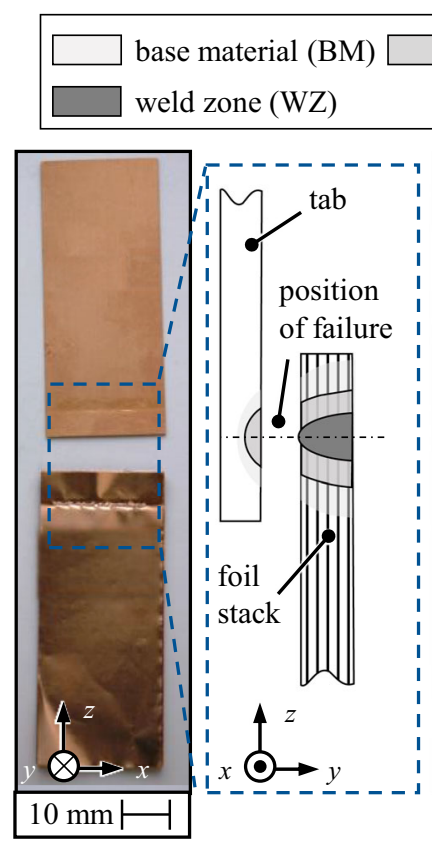

a)

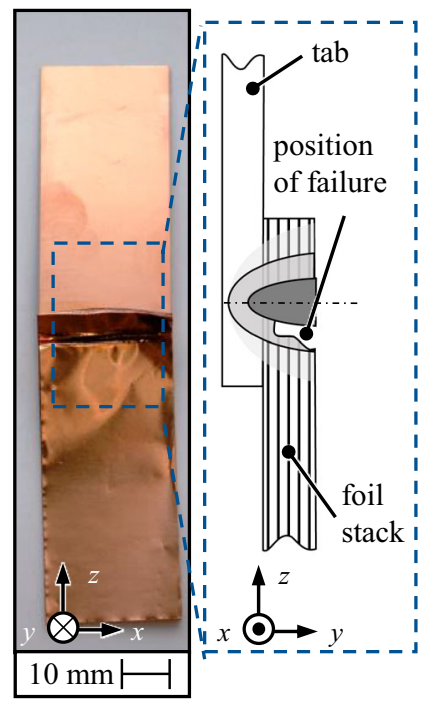

b)
Fig. 7 Observed fracture modes in the tensile tests: insufficent penetration in the tab (a), cracks in the HAZ (b) 

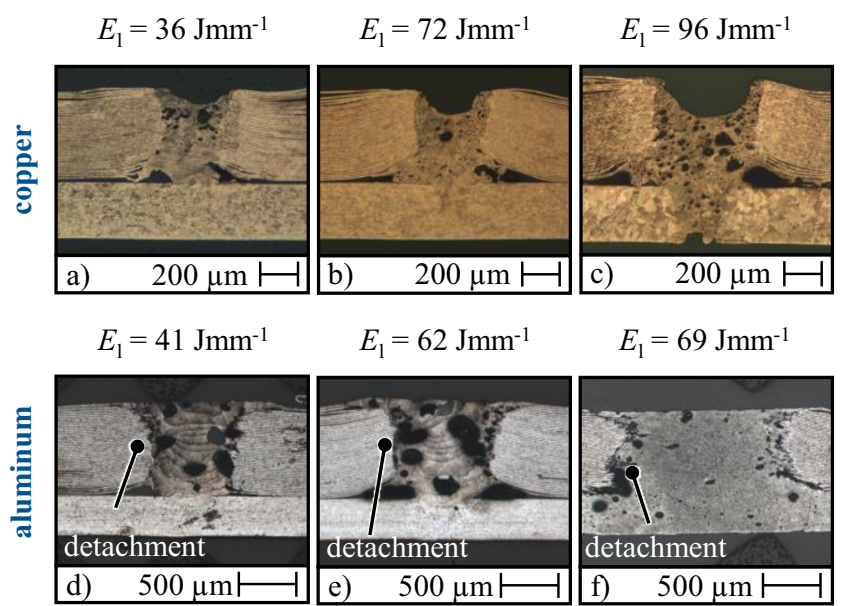

$E_{1}=69 \mathrm{Jmm}^{-1}$

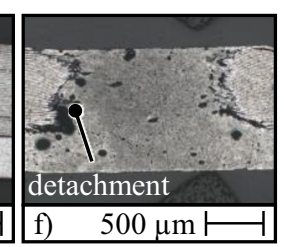

Fig. 8 Cross sections of the copper $(\mathrm{a}-\mathrm{c})$ and the aluminum weld seams (d-f) for different line energies $E_{1}$

fluctuations of the weld seam area and more significant deviations in tensile shear strengths occurred.

Directly next to weld seams, small gaps between the foil stack and the arrester tab were found (see Fig. 8). The clamping device for the welding experiments was designed to ensure a zero gap between the foil stack and the arrester tab. However, for process-related reasons, a welding recess is required in the clamping bridge. Therefore, no clamping force was applied directly next to the welding zone. The gaps between the foil stacks and the arrester tabs occurred due to the thermal expansion of the foils during welding and were mainly visible at high energy inputs per unit length. No direct correlation between the measured tensile shear forces and the gaps was found in the conducted experiments. Since the boundary conditions of the specimen fixation were the same for all parameter sets, the gaps were not evaluated in more detail.

The overall strength of the copper specimens was around five times as high as for the aluminum samples. Regarding the strength of the base materials, this is a significant difference. Based on the strengths of a single foil, determined in preliminary tests, a smaller difference was expected between the two materials. Therefore, it is concluded that the welding process caused a weakening of the aluminum foils. Regarding the cross sections of the aluminum foil stacks (see Fig. 8d-f), detachments of the seam from the foils were visible at the edges of the weld zone. Those seam irregularities were found in all examined specimens. The location of the fracture in the shear tests was congruent with the position of the detachments. Similar seam defects were already observed when welding 15 aluminum foils with a laser beam source emitting in the IR wavelength spectrum [27]. These detachments of the weld seams were weak points of the joint and were the starting point for foil ruptures causing the relatively low tensile strength of the aluminium specimens. In general, aluminum alloys show a high solidification shrinkage due to a high thermal expansion coefficient [40]. The rigid clamping impeded the material to post-flow, and detachments were formed in the weld seam. Besides that, embrittlement of the aluminum in the adjacent seam area can cause a decrease in mechanical strength [41]. A solution to reduce this seam defect may be an improved clamping device, which allows the material to post-flow. Another possibility can be the use of an adapted laser intensity profile to reduce the heat gradient [42].

In addition to the increasing weld depth, another phenomenon was observed. The seam collapse and the number of seam irregularities, like pores, increased with the overall energy input (increase of $P$, reduction of $v$ ). On the one hand, the bonding increased due to a higher welding depth, and on the other hand, the seam strength was reduced by seam defects and notches. Therefore, the tensile shear force converged to the described boundary value. With regard to the application in LIBs, parameter sets leading to strong over welds were excluded in the conducted experiments. Thus, the maximum energy input per unit length was limited. It is expected that with further increasing line energies per unit length, the tensile shear strengths would decrease. Similar observations were made for welding thin steel foils using a pulsed welding strategy. Within the experiments of VENTRELLA et al. the seam strength increased first with an increasing energy input per unit length but decreased after a certain level [43]. Concerning the mechanical seam properties as well as the processing times, parameter sets with high welding speeds resulting in an energy input per unit length above $65 \mathrm{~J} \mathrm{~mm}^{-1}$ within the pre-defined parameter window are recommended for copper.

\subsection{Requirements concerning the mechanical strength}

Laser beam welding of foil stacks to a conductor tab is a feasible joining process, particularly in the production of pouch and hard-case cells. Regarding the mechanical design of the joint, the determined mechanical seam strengths must be related to the application requirements. Key design criteria for the strength of welded contacts in battery cells are testing standards for the load on battery cells in use [44]. According to [45], there are different authorization standards to perform safety tests for LIBs depending on their application. These tests aim at representing typical loads and at identifying critical points of the cells in laboratory pre-tests. This includes the reproduction of extreme and worst-case scenarios, such as car crashes or a mechanical penetration of the cell. For the application of LIBs in EVs, a crash poses 
saftey issues on the cell. [45] According to [44], testing standards based on crash scenarios are a key design criterion for the strength of welded contacts in battery cells to account for all requirements of the accreditation process of LIBs.

ISO 6469-1 provides testing methods for examining the occuring loads on LIBs. For vehicles with a total mass below $3500 \mathrm{~kg}$, a maximum longitudinal acceleration of $28 \mathrm{~g}$ and a maximum transversal acceleration of $16 \mathrm{~g}$ act on the cells during a test cycle as defined in ISO 6469-1. The maximum combined acceleration $a_{\max }$ corresponds to $a_{\max }=32 \cdot g=32 \cdot 9.81 \mathrm{~ms}^{-2}$. According to WISCH et al. the acceleration in real car crashes is below $20 \mathrm{~g}$ to $30 \mathrm{~g}$ [46]. In the assumed worst-case scenario, the weld between the arrester tab and the stack of current collector foils is completely loaded with the inertial force of the total stack. The minimum strength $F_{\min }$ of the joint is then calculated from the acceleration $a_{\max }$ and the stack mass $m_{\mathrm{s}}$ according to $F_{\min }=a_{\max } \cdot m_{\mathrm{s}}$.

In Fig. 9, the dependency of $F_{\min }$ on the mass of the stacks for different acceleration cases is shown. The measured maximum strengths from the experiments of this study are also plotted. Depending on the chosen acceleration, different permissible stack masses result.

The masses of different sample cell-stacks were calculated and are shown in Fig. 9. For the calculation of the cell masses, three different large-format cell sizes (cell scenario I, II, III) with capacities $C=34 \mathrm{Ah}, 49 \mathrm{Ah}$, and $81 \mathrm{Ah}$, based on commercial common capacities for EV were used as examples [47]. All calculations were performed with a stack configuration of 41 anodes and 40 cathodes. The used cell materials (see Tables 9 and 8), the

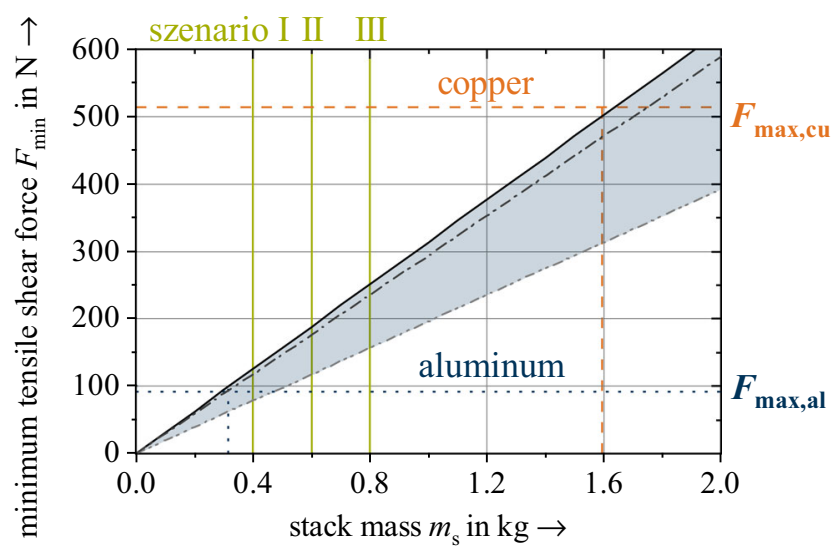

range of acceleration $a$ $a=32 \cdot \mathrm{g}-\cdot-\cdot-\cdot a=30 \cdot \mathrm{g} \quad-\cdots-\cdots-a=20 \cdot \mathrm{g}$

Fig. 9 Calculated minimum seam strength $F_{\min }$ over the stack masses $m_{\mathrm{s}}$ for a crash scenario using different accelerations $a$. Three different cell scenarios I, II, and III corresponding to different capacities $C=$ $34 \mathrm{Ah}, 49 \mathrm{Ah}$, and $81 \mathrm{Ah}$ are shown to classify the maximum measured strengths $F_{\max }$ for a copper and an aluminum stack geometries (see Table 10) and the calculation formulae (see Eqs. 1a to 2) are documented in the Appendix.

The highest measured tensile shear force for copper was $514 \mathrm{~N}$, which exceeds the strength requirements for all listed masses along the entire acceleration range. For aluminum, the seams in the shown set-up only meet the strength requirements up to a stack weight of $293 \mathrm{~g}$. Therefore, for larger masses, contacting via two weld seams on the aluminum side or dividing the cell stack into two thinner stacks is recommended.

The design of the battery cell with regard to the mechanical properties must take into account the loadbearing capacity of the internal contact points. The calculation method shown for the minimum strengths provides a framework on which the length of the seams or the number of contact points can be calculated. It has to be considered that the calculation approach is based on the simplification of possible occurring loads. The method is not recommended to calculate the seam strength under dynamic loads, such as vibrations.

\section{Conclusion and outlook}

For the application of LBW for the cell internal contacting of LIBs, it is necessary to understand the process and to analyze the cause-effect relationships with the target variables. One objective is to ensure the mechanical strength of the weld seams, as this, together with a low electrical resistance, is a crucial criterion. In the context of this work, the tensile strength of cell contacts produced using green laser radiation was evaluated. First, parameter windows and different welding regimes for joining stacks of 40 metal foils with an arrester tab were identified. Subsequently, the influences of the individual parameters on the tensile shear force as well as the strength values were examined. The main observations from this work are:

1. The mechanical strength of the copper welds was about five times as high as for the aluminum welds. The maximum mean strength was $514 \mathrm{~N}$ for copper and $92 \mathrm{~N}$ for aluminum stacks.

2. Within the considered parameter range, the tensile shear force increased for both materials when the power $P$, the pulse frequency $f_{\mathrm{P}}$, and the pulse duration $t_{\mathrm{P}}$ were increased, and the welding speed $v$ was decreased.

3. For both materials, the pulse duration had the most decisive impact on the seam strength. A dependence between the energy input per unit length and the seam strength was found and quantified.

4. The tensile shear force was determined by the welding depth and the seam collapse. These two effects cancel each other out. Overall, the tensile shear force 
converged towards an upper boundary of the tensile shear force.

5. The mechanical strength of the aluminum joint was reduced by the occurrence of detachments of the weld seams from the foils.

6. The worst-case scenario of a crash can be used to design the cell internal contact point for EV applications. An adjustment of the weld seam geometry or the weld length allows an application-specific modification.

In future investigations, approaches to reduce the detachments of the weld seams from the foils within the aluminum samples should be considered. Further investigations should clarify if other input variables, such as the application of protective gas or the clamping force, cause a significant impact on the mechanical strength of aluminum foil stacks. Besides the mechanical properties, the electrical resistance is an important seam property of the cell internal contact. Therefore, the electrical properties of the welded seams have to be evaluated. The thermal boundary conditions have to be taken into account for a comprehensive joining process design.

\section{Appendix}

Table 3 Characteristics of the laser system

\begin{tabular}{ll}
\hline Parameter & Value \\
\hline Mode of operation & Continuous wave (cw) \\
Maximum laser power $P_{\max }$ & $1000 \mathrm{~W}$ \\
Wavelength $\lambda$ & $515 \mathrm{~nm}$ \\
Fiber core diameter $d_{\mathrm{cf}}$ & $50 \mu \mathrm{m}$ \\
Aspect ratio $A R$ & $1: 2.93$ \\
Focus diameter $d_{\mathrm{f}}^{*}$ & $147 \mu \mathrm{m}$ \\
Field size & $138 \times 134 \mathrm{~mm}$
\end{tabular}

${ }^{*}$ Calculated from $d_{\mathrm{cf}} \cdot A R=d_{\mathrm{f}}$

Table 4 Parameters for the conduction of the tensile shear strength tests

\begin{tabular}{ll}
\hline Parameter & Value \\
\hline Test speed $v_{\mathrm{t}}$ & $50 \mathrm{~mm} \mathrm{~min}^{-1}$ \\
Pre-loading speed $v_{\text {pre }}$ & $5 \mathrm{~mm} \mathrm{~min}^{-1}$ \\
Pre-load $F_{\text {pre }}$ & $1 \mathrm{~N}$ \\
Threshold for strength cut-off $F_{\mathrm{t}}$ & $90 \% F_{\max }$ \\
Testing length $l_{\mathrm{t}}$ & $57.5 \mathrm{~mm}$ \\
Clamping length $l_{\mathrm{c}}$ & $25 \mathrm{~mm}$ \\
\hline
\end{tabular}

Table 5 Parameter sets of the CCD experimental design for the material copper

\begin{tabular}{|c|c|c|c|c|}
\hline $\begin{array}{l}\text { Set } \\
\text { number }\end{array}$ & $\begin{array}{l}\text { Power } P \\
\text { in } \mathrm{W}\end{array}$ & 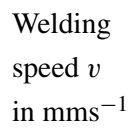 & $\begin{array}{l}\text { Frequency } f \\
\text { in } \mathrm{Hz}\end{array}$ & $\begin{array}{l}\text { Pulse duration } \\
t_{\mathrm{p}} \text { in } \mathrm{ms}\end{array}$ \\
\hline 1 & 800 & 10.0 & 150.0 & 2.0 \\
\hline 2 & 900 & 5.0 & 150.0 & 3.0 \\
\hline 3 & 800 & 5.0 & 200.0 & 3.0 \\
\hline 4 & 850 & 4.0 & 175.0 & 2.5 \\
\hline 5 & 850 & 7.5 & 175.0 & 3.2 \\
\hline 6 & 850 & 7.5 & 139.8 & 2.5 \\
\hline 7 & 850 & 11.0 & 175.0 & 2.5 \\
\hline 8 & 780 & 7.5 & 175.0 & 2.5 \\
\hline 9 & 850 & 7.5 & 210.3 & 2.5 \\
\hline 10 & 850 & 7.5 & 175.0 & 1.8 \\
\hline 11 & 900 & 10.0 & 200.0 & 3.0 \\
\hline 12 & 800 & 5.0 & 150.0 & 2.0 \\
\hline 13 & 850 & 7.5 & 175.0 & 2.5 \\
\hline 14 & 900 & 10.0 & 150.0 & 2.0 \\
\hline 15 & 900 & 10.0 & 200.0 & 2.0 \\
\hline 16 & 900 & 5.0 & 150.0 & 2.0 \\
\hline 17 & 921 & 7.5 & 175.0 & 2.5 \\
\hline 18 & 800 & 10.0 & 150.0 & 3.0 \\
\hline 19 & 800 & 10.0 & 200.0 & 3.0 \\
\hline 20 & 800 & 5.0 & 200.0 & 2.0 \\
\hline 21 & 900 & 5.0 & 200.0 & 2.0 \\
\hline 22 & 800 & 5.0 & 150.0 & 3.0 \\
\hline 23 & 900 & 10.0 & 150.0 & 3.0 \\
\hline 24 & 900 & 5.0 & 200.0 & 3.0 \\
\hline 25 & 800 & 10.0 & 200.0 & 2.0 \\
\hline
\end{tabular}


Table 6 Parameter sets of the CCD experimental design for the material aluminum

\begin{tabular}{|c|c|c|c|c|}
\hline $\begin{array}{l}\text { Set } \\
\text { number }\end{array}$ & $\begin{array}{l}\text { Power } P \\
\text { in } \mathrm{W}\end{array}$ & $\begin{array}{l}\text { Welding } \\
\text { speed } v \\
\text { in } \mathrm{mms}^{-1}\end{array}$ & $\begin{array}{l}\text { Frequency } f \\
\text { in } \mathrm{Hz}\end{array}$ & $\begin{array}{l}\text { Pulse duration } \\
t_{\mathrm{p}} \text { in } \mathrm{ms}\end{array}$ \\
\hline 1 & 875 & 6.4 & 225.0 & 2.5 \\
\hline 2 & 875 & 12.0 & 260.3 & 2.5 \\
\hline 3 & 925 & 8.0 & 200.0 & 3.0 \\
\hline 4 & 925 & 8.0 & 200.0 & 2.0 \\
\hline 5 & 825 & 8.0 & 200.0 & 3.0 \\
\hline 6 & 825 & 8.0 & 200.0 & 2.0 \\
\hline 7 & 825 & 16.0 & 200.0 & 2.0 \\
\hline 8 & 925 & 16.0 & 200.0 & 2.0 \\
\hline 9 & 925 & 16.0 & 200.0 & 3.0 \\
\hline 10 & 825 & 16.0 & 200.0 & 3.0 \\
\hline 11 & 825 & 8.0 & 250.0 & 3.0 \\
\hline 12 & 925 & 8.0 & 250.0 & 2.0 \\
\hline 13 & 825 & 8.0 & 250.0 & 2.0 \\
\hline 14 & 925 & 8.0 & 250.0 & 3.0 \\
\hline 15 & 825 & 16.0 & 250.0 & 2.0 \\
\hline 16 & 825 & 16.0 & 250.0 & 3.0 \\
\hline 17 & 925 & 16.0 & 250.0 & 2.0 \\
\hline 18 & 925 & 16.0 & 250.0 & 3.0 \\
\hline 19 & 875 & 12.0 & 189.8 & 2.5 \\
\hline 20 & 875 & 17.6 & 225.0 & 2.5 \\
\hline 21 & 875 & 12.0 & 225.0 & 2.5 \\
\hline 22 & 946 & 12.0 & 225.0 & 2.5 \\
\hline 23 & 875 & 12.0 & 225.0 & 3.2 \\
\hline 24 & 875 & 12.0 & 225.0 & 1.8 \\
\hline 25 & 805 & 12.0 & 225.0 & 2.5 \\
\hline
\end{tabular}

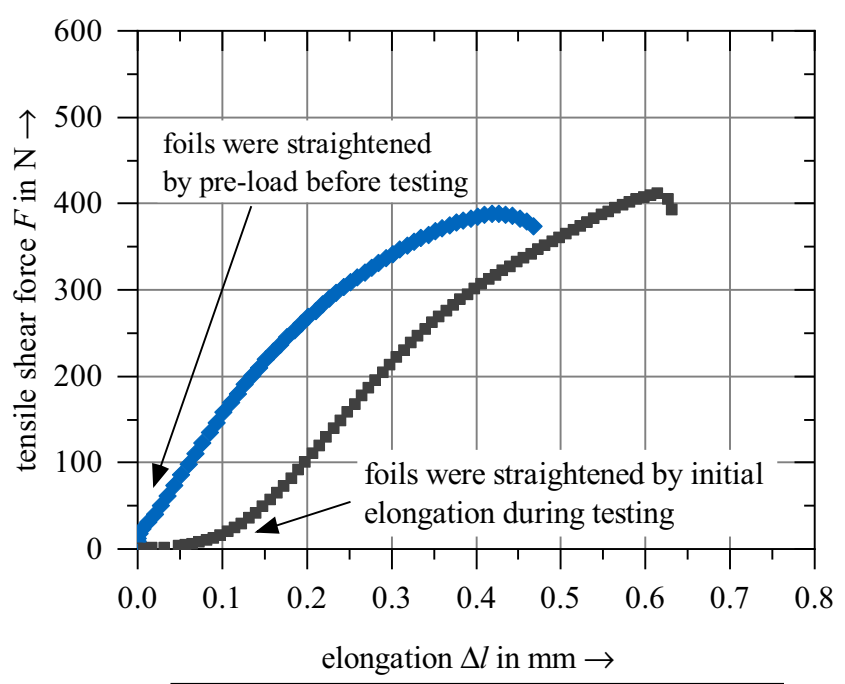

- lap shear test with a pre-load of $F_{\text {pre }}=1 \mathrm{~N}$
- lap shear test without a pre-load

Fig. 10 Comparison of exemplary test curves of lap shear tests for the copper samples with and without applying a pre-load of $F_{\text {pre }}=1 \mathrm{~N}$. The applied pre-load ensured a complete straightening of the foils before testing
Table 7 Calculated mass of the sample cell stacks filled with electrolyte and the corresponding cell capacity

\begin{tabular}{lll}
\hline Cell scenario & $\begin{array}{l}\text { Mass of the total } \\
\text { cell stack filled with } \\
\text { electrolyte } m_{\mathrm{s}}\end{array}$ & $\begin{array}{l}\text { Theoretical cell } \\
\text { capacity } C\end{array}$ \\
\hline I & $432 \mathrm{~g}$ & $34 \mathrm{Ah}$ \\
II & $637 \mathrm{~g}$ & $49 \mathrm{Ah}$ \\
III & $1035 \mathrm{~g}$ & $81 \mathrm{Ah}$ \\
\hline
\end{tabular}

Table 8 Specifications of the cell materials used to calculate the mass on the weld seams

\begin{tabular}{|c|c|c|c|}
\hline & Density $\rho_{\mathrm{i}}$ in $\mathrm{gcm}^{-3}$ & $\begin{array}{l}\text { Theoretica } \\
\text { capacity } c_{\mathrm{i}}\end{array}$ & \\
\hline Anode & Current collector & 8.96 & - \\
\hline & Graphite & $2.24[48]$ & $370[48]$ \\
\hline & Carbon black & 2.25 & - \\
\hline & $\begin{array}{l}\text { Polyvinylidenfluoride } \\
\text { (PVDF) }\end{array}$ & 1.80 & - \\
\hline Cathode & Current collector & 2.70 & - \\
\hline & $\begin{array}{l}\text { Lithium-nickel-manganese- } \\
\text { cobalt-oxide } 622 \\
\text { (NMC 622) }\end{array}$ & $4.70[49]$ & 180 [49] \\
\hline & Carbon black & 2.25 & - \\
\hline & PVDF & 1.80 & - \\
\hline Electroly & yte (LP572, BASF, Germany) & 1.19 & - \\
\hline $\begin{array}{r}\text { Separato } \\
(34 \% \mathrm{p}\end{array}$ & $\begin{array}{l}\text { or polypropylene } \\
\text { porosity) }\end{array}$ & 0.92 & - \\
\hline
\end{tabular}




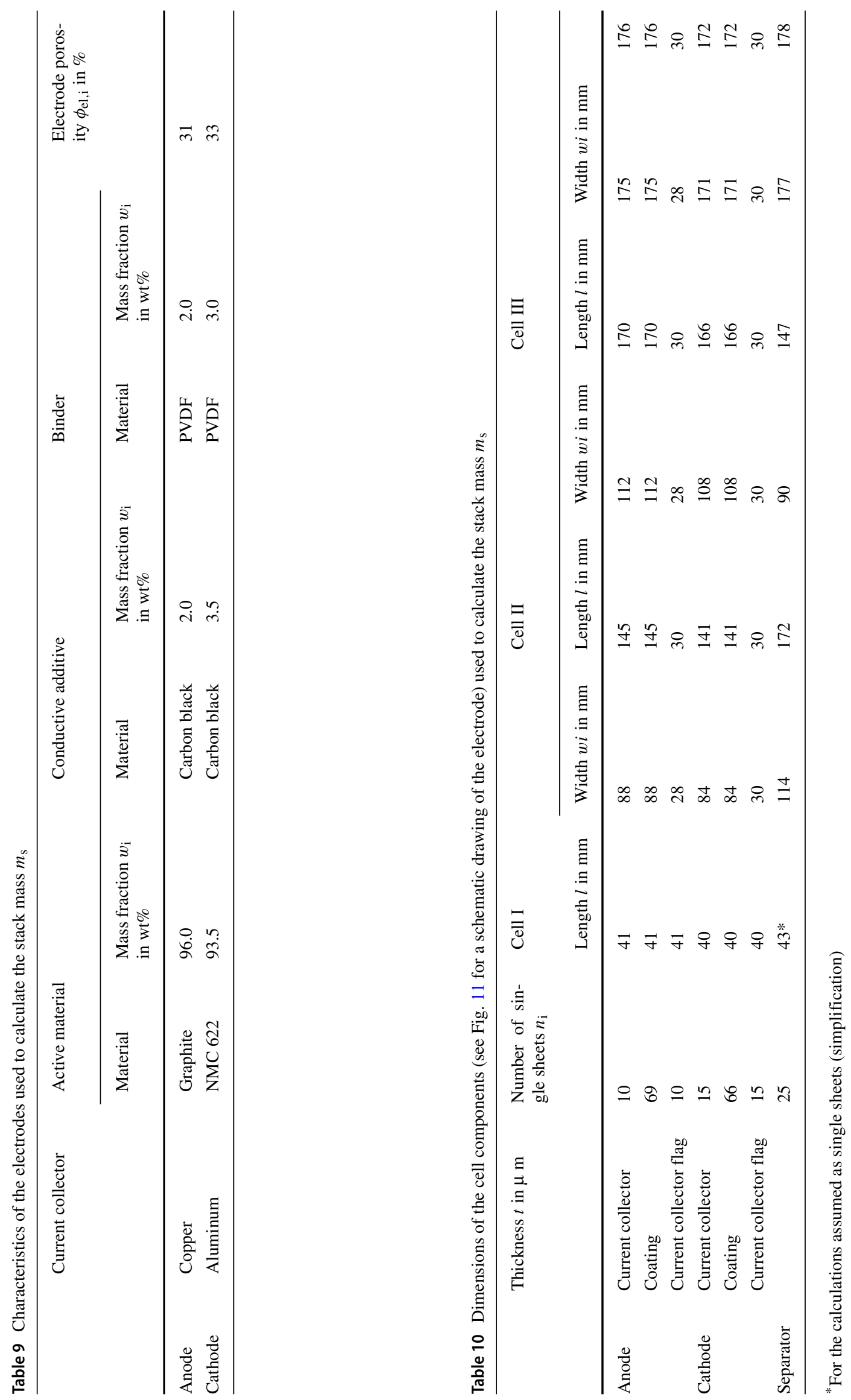




\section{Formulae to calculate the masses of the cell stacks in Table 7}

Mass on the weld seams $m_{\mathrm{s}}=m_{\mathrm{e}, 1}+m_{\mathrm{e}, 2}+m_{\mathrm{sep}}$

Mass of the electrode $m_{\mathrm{e}, i}=m_{\mathrm{coa}, \mathrm{i}}+m_{\mathrm{cc}, \mathrm{i}}$

Mass of the current col. $m_{\mathrm{cc}, \mathrm{i}}=V_{\mathrm{cc}, \mathrm{i}} \cdot \rho_{\mathrm{cc}} \cdot n_{\mathrm{e}, \mathrm{i}}$

Mass of the coating $m_{\mathrm{coa}, \mathrm{i}}=V_{\mathrm{coa}, \mathrm{i}} \cdot n_{\mathrm{e}, \mathrm{i}} \cdot 2 \cdot\left(\left(1-\phi_{\mathrm{coa}, \mathrm{i}}\right) \cdot \rho_{\mathrm{coa}, \mathrm{i}}+\phi_{\mathrm{coa}, \mathrm{i}} \cdot \rho_{\mathrm{el}}\right)$

Density of the coating $\rho_{\text {coa }, \mathrm{i}}=\sum_{\mathrm{j}=1}^{n_{\text {comp }}} w_{\mathrm{j}} \cdot \rho_{\text {comp }, \mathrm{j}}$

Mass of the separator $m_{\text {sep }}=V_{\text {sep }} \cdot n_{\text {sep }} \cdot\left(\left(1-\phi_{\text {sep }}\right) \cdot \rho_{\text {sep }}+\phi_{\text {sep }} \cdot \rho_{\text {elec }}\right)$

with: volume $V_{\mathrm{i}}$, density $\rho_{\mathrm{i}}$, number of components i $n_{\mathrm{i}}$, porosity $\phi_{\mathrm{i}}$, mass fraction $w_{\mathrm{i}}$

\section{Formula to calculate the cell capacity in Table 7}

Nominal cell capacity $C=V_{\text {active material }} \cdot c \cdot n_{\mathrm{c}} \cdot 2=t_{\text {coa }} \cdot w i_{\mathrm{e}, 2} \cdot l_{\mathrm{e}, 2} \cdot \phi_{\mathrm{e}, 2} \cdot w_{\mathrm{NMC} 622} \cdot c_{\mathrm{NMC}} 622 \cdot n_{\mathrm{e}, 2} \cdot 2$

with: specific capacity $c$, thickness $t$, width $w i$, length $l$

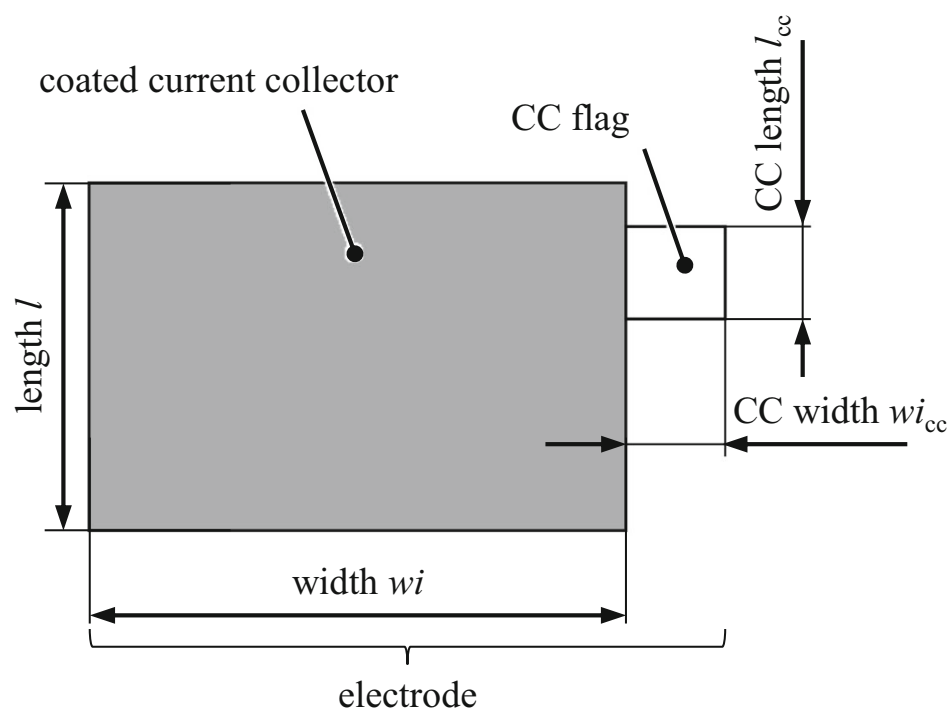

a)

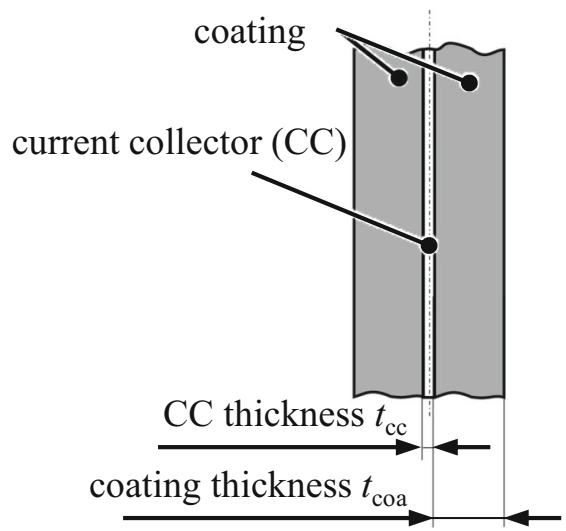

b)

Fig. 11 Schematic drawing of a single electrode-sheet with a double-sided coating: (a) top-view of the electrode-sheet and (b) side view of the electrode-sheet 
Acknowledgements The results presented were gathered within the project InQuZell (03XP0342A), funded by the German Federal Ministry of Education and Research (BMBF). For the calculations, the materials and the dimensions of the large-format hard-case cells produced in the project InnoCase (03XP0207F) were used. InnoCase is financially supported by the BMBF. We would like to thank the BMBF and the Project Management Organisation Jülich (PTJ) for their support and the effective and trusting cooperation.

Author contribution Sophie Grabmann: conceptualization, formal analysis, investigation, methodology, software, visualization, writingoriginal draft, writing-review and editing. Johannes Kriegler: conceptualization, writing-review and editing. Felix Harst: investigation. Florian J. Günter: supervision, writing-review and editing. Michael F. Zaeh: project administration, supervision, writing-review and editing.

Funding Open Access funding enabled and organized by Projekt DEAL. This research was funded by the German Federal Ministry of Education and Research (BMBF).

\section{Declarations}

Ethical approval Not applicable.

Consent to participate The authors agree to participate in the submission and publication.

Consent to publish The authors confirm publishing the content of the paper.

Competing interests The authors declare that they have no competing interests.

Data Availability Not applicable.

Open Access This article is licensed under a Creative Commons Attribution 4.0 International License, which permits use, sharing, adaptation, distribution and reproduction in any medium or format, as long as you give appropriate credit to the original author(s) and the source, provide a link to the Creative Commons licence, and indicate if changes were made. The images or other third party material in this article are included in the article's Creative Commons licence, unless indicated otherwise in a credit line to the material. If material is not included in the article's Creative Commons licence and your intended use is not permitted by statutory regulation or exceeds the permitted use, you will need to obtain permission directly from the copyright holder. To view a copy of this licence, visit http://creativecommons. org/licenses/by/4.0/.

\section{References}

1. Zubi G, Dufo-López R, Carvalho M, Pasaoglu G (2018) The lithium-ion battery: State of the art and future perspectives 89:292-308. https://doi.org/10.1016/j.rser.2018.03.002

2. Blomgren GE (2017) The development and future of lithium ion batteries 164(1):A5019-A5025. https://doi.org/10.1149/2.025170 1 jes

3. Deimede V, Elmasides C (2015) Separators for lithium-ion batteries: A review on the production processes and recent developments 3(5):453-468. https://doi.org/10.1002/ente.201402215
4. Kraytsberg A, Ein-Eli Y (2016) Conveying advanced li-ion battery materials into practice the impact of electrode slurry preparation skills 6(21):1-23. https://doi.org/10.1002/aenm.201600655

5. Haselrieder W, Westphal B, Bockholt H, Diener A, Hoeft S, Kwade A (2015) Measuring the coating adhesion strength of electrodes for lithium-ion batteries 60:1-8. https://doi.org/10.1016/j. ijadhadh.2015.03.002

6. Zhu P, Gastol D, Marshall J, Sommerville R, Goodship V, Kendrick E (2021) A review of current collectors for lithium-ion batteries 485 229321-1-22932-21. https://doi.org/10.1016/j.jpow sour.2020.229321

7. Kwade A, Haselrieder W, Leithoff R, Modlinger A, Dietrich F, Droeder K (2018) Current status and challenges for automotive battery production technologies 3(4):290-300. https://doi.org/10.1038/s41560-018-0130-3

8. Schreiner D, Zuend T, Guenter FJ, Kraft L, Stumper B, Linsenmann F, Schuessler M, Wilhelm R, Jossen A, Reinhart G, Gasteiger HA (2021) Comparative evaluation of lmr-ncm and nca cathode active materials in multilayer lithium-ion pouch cells: Part i. production, electrode characterization, and formation 168(3):030507-1-030507-21. https://doi.org/10.1149/1945-7111/abe50c

9. Kriegler J, Binzer M, Zaeh MF (2021) Process strategies for laser cutting of electrodes in lithium-ion battery production 33(1):012006-1-012006-8

10. Schroeder R, Aydemir M, Seliger G (2017) Comparatively assessing different shapes of lithium-ion battery cells 8:104-111. https://doi.org/10.1016/j.promfg.2017.02.013

11. Grabmann S, Tomcic L, Zaeh MF (2020) Laser beam welding of copper foil stacks using a green high power disk laser 94:582-586. https://doi.org/10.1016/j.procir.2020.09.080

12. Knoche T, Reinhart G (2015) Electrolyte filling of largescale lithium-ion batteries: challenges for production technology and possible approaches 794:11-18. https://doi.org/10.4028/www. scientific.net/AMM.794.11

13. Das A, Li D, Williams D, Greenwood D (2018) Joining technologies for automotive battery systems manufacturing 9(2): 22. https://doi.org/10.3390/wevj9020022. PII: wevj9020022

14. Balz I, Rosenthal E, Reimer A, Turiaux M, Schiebahn A, Reisgen U (2019) Analysis of the thermo-mechanical mechanism during ultrasonic welding of battery tabs using high-speed image capturing 63(6):1573-1582. https://doi.org/10.1007/s40194-01900788-z

15. Neppiras EA (1965) Ultrasonic welding of metals 3(3):128-135. https://doi.org/10.1016/S0041-624X(65)80003-8

16. Lee SS, Kim TH, Hu SJ, Cai WW, Jeffrey A, Li J (2013) Characterization of joint quality in ultrasonic welding of battery tabs 135(2). https://doi.org/10.1115/1.4023364

17. Kim TH, Yum J, Hu SJ, Spicer JP, Abell JA (2011) Process robustness of single lap ultrasonic welding of thin, dissimilar materials 60(1):17-20. https://doi.org/10.1016/j.cirp.2011.03.016

18. Choi S, Zhang G, Fuhlbrigge TA, Nidamarthi S Vibration anaysis in robotic ultrasonic welding for battery assembly. In: 2012 IEEE International Conference on Technologies for Practical Robot Applications (TePRA). IEEE. https://doi.org/10.1109/tepra. 2012.6215674

19. Wu B, Yang Y, Liu D, Niu C, Gross M, Seymour L, Lee H, Le PML, Vo TD, Deng ZD, Dufek EJ, Whittingham MS, Liu J, Xiao J (2019) Good practices for rechargeable lithium metal batteries 166(16):A4141-A4149. https://doi.org/10.1149/2.0691916jes

20. Kang B, Cai W, Tan CA (2014) Vibrational energy loss analysis in battery tab ultrasonic welding 16(2):218-232. https://doi.org/10.1016/j.jmapro.2013.10.008 
21. Zaeh MF, Moesl J, Musiol J, Oefele F (2010) Material processing with remote technology revolution or evolution? 5:1933. https://doi.org/10.1016/j.phpro.2010.08.119

22. Patschger A, Bliedtner J, Hild M, Pierre Bergmann J (2012) Flexible and efficient laser remote welding of ultra-thin metal foils 24(5):052005-1-052005-8. https://doi.org/10.2351/1.4746453

23. Patschger A, Bliedtner J, Bergmann JP (2014) Process-limiting factors and characteristics of laser-based micro welding 56:740 749. https://doi.org/10.1016/j.phpro.2014.08.081

24. Miyamoto I, Knorovsky GA (2011) Laser microwelding. In: Zhou $\mathrm{Y}$ (ed) Microjoining and nanojoining, woodhead publishing in materials. Woodhead Pub. and Maney Pub, pp 345-417

25. Thomy C, Moeller F, Vollertsen F (2010) Distortion effects in micro welding with fibre laser. In: Proceedings of the International Congress of Applications of Lasers and Electro-Optics (ICALEO 2010), no. 613 in LIA. ICALEO and International Congress on Applications of Lasers \& Electro-Optics and Laser Materials Processing Conference and Laser Microprocessing Conference and Nanomanufacturing Conference, Laser Institute of America, pp 85-90. https://doi.org/10.2351/1.5062128

26. Schedewy R, Beyer E, Brenner B, Standfuss J (2011) Prospects of welding foils with solid state laser for lithium-ion batteries. In: Proceedings of the International Congress of Applications of Lasers and Electro-Optics (ICALEO 2011). Laser Institute of America, pp 817-824. https://doi.org/10.2351/1.5062332

27. Engelhardt T, Brandner M, Weber R, Graf T (2015) Influence of welding parameters and stack configuration on pore formation of laser welded aluminum foil stacks. In: Proceeding of lasers in manufacuturing 2015. scientific society for laser technology e.v. (WLT e.v.)

28. de Bono P, Blackburn J (2015) Laser welding of copper and aluminium battery interconnections. In: Green M, Rose C (eds) Industrial Laser Applications Symposium (ILAS 2015), SPIE Proceedings. SPIE, pp 96570M1-96570M13. https://doi.org/10.1117/12.2176048

29. Zhang ZJ, Ramadass P (2009) Lithium-ion battery separators1. In: Yoshio M, Brodd RJ, Kozawa A (eds) Lithium-Ion Batteries. Springer, New York, pp 1-46. https://doi.org/10.1007/978-0-38734445-4-20

30. Mohseni H, Schmoeller M, Zaeh MF (2019) A novel approach for welding metallic foils using pulsed-laser radiation in the field of battery production. In: Proceedings of the Conference Lasers in Manufacturing 2019. Scientific Society for Laser Technology e.V. (WLT e.V.)

31. Pelaprat JM, Zediker M, Finuf M, Fritz R (2020) The blue light district 17(1):61-65. https://doi.org/10.1002/phvs.202000005

32. Kaiser E, Pricking S, Stolzenburg C, Killi A (2015) Sputterfree and reproducible laser welding of electric or electronic copper contacts with green laser. In: Proceeding of lasers in manufacuturing 2015. scientific society for laser technology e.v. (WLT e.v.)

33. Pricking S, Huber R, Klausmann K, Kaiser E, Stolzenburg C, Killi A (2016) High-power cw and long-pulse lasers in the green wavelength regime for copper welding. In: Dorsch F, Kaierle S (eds) High-Power Laser Materials Processing: Lasers, Beam Delivery, Diagnostics, and Applications V, SPIE Proceedings. SPIE, pp 97410G-1-97410G-7. https://doi.org/10.1117/12.2213293

34. Haubold M, Ganser A, Eder T, Zaeh MF (2018) Laser welding of copper using a high power disc laser at green wavelength 74:446-449. https://doi.org/10.1016/j.procir.2018.08.161
35. Finuf MJ, Gray B, Fritz R, Pelaprat JM, Zediker MS (2017) Laser welding copper with hight power $\mathrm{cw}$ blue laser. In: Proceedings of the International Congress of Applications of Lasers and Electro-Optics (ICALEO 2017). Laser Institute of America. https://doi.org/10.2351/1.5138176

36. Zediker MS, Fritz RD, Finuf MJ, Pelaprat JM (2019) Stable keyhole welding of $1 \mathrm{~mm}$ thick copper with a $600 \mathrm{w}$ blue laser system 31(2):022404-1-022404-7. https://doi.org/10.2351/1.509 6092

37. Gale WF, Totemeier TC (2004) Smithells metals reference book, 8 edn. Elsevier/Butterworth-Heinemann

38. Montgomery DC (2020) Design and analysis of experiments, 20th edn. Wiley

39. Das A, Fritz R, Finuf M, Masters I (2020) Blue laser welding of multi-layered aisi 3161 stainless steel micro-foils 132:106498106514. https://doi.org/10.1016/j.optlastec.2020.106498

40. Pequet C, Rappaz M, Gremaud M (2002) Modeling of microporosity, macroporosity, and pipe-shrinkage formation during the solidification of alloys using a mushy-zone refinement method: applications to aluminum alloys 33(7):2095-2106

41. Hagenlocher C, Sommer M, Fetzer F, Weber R, Graf T (2018) Optimization of the solidification conditions by means of beam oscillation during laser beam welding of aluminum 160:11781185. https://doi.org/10.1016/j.matdes.2018.11.009

42. Liebl S, Stadter C, Ganser A, Zaeh MF (2017) Numerical simulation of laser beam welding using an adapted intensity distribution 29(2):022405-1-022405-8. https://doi.org/10.2351/1.4983235

43. Ventrella VA, Berretta JR, de Rossi W (2010) Pulsed nd:yag laser seam welding of aisi 3161 stainless steel thin foils 210(14):1838-1843. https://doi.org/10.1016/j.jmatprotec.2010. 06.015

44. Schmitz P (2019) Electrical connection of cylindrical lithium-ion cells for the manufacturing of energy storage systems

45. Ruiz V, Pfrang A, Kriston A, Omar N, Van den bossche P, BoonBrett L (2018) A review of international abuse testing standards and regulations for lithium ion batteries in electric and hybrid electric vehicles 81:1427-1452. https://doi.org/10.1016/j.rser.2017. 05.195

46. Wisch M, Ott J, Thomson R, Léost Y, Abert M, Yao J (2014) Recommendations and guidelines for battery crash safety and post-crash safe handling

47. Hettesheimer T, Thielmann A, Neef C, Moeller KC, Wolter M, Lorentz V, Gepp M, Wenger M, Prill T, Zausch J, Kitzler P, Montnacher J, Miller M, Hagen M, Fanz P, Tübke J (2017) Entwicklungsperspektiven fuer zellformate von lithium-ionenbatterien in der elektromobilitaet. http://publica.fraunhofer.de/ dokumente/N-477577.html

48. Andre D, Hain H, Lamp P, Maglia F, Stiaszny B (2017) Future high-energy density anode materials from an automotive application perspective 5(33):17174-17198. https://doi.org/10. 1039/C7TA03108D

49. Li J, Du Z, Ruther RE, AN SJ, David LA, Hays K, Wood M, Phillip ND, Sheng Y, Mao C, Kalnaus S, Daniel C, Wood DL (2017) Toward low-cost, high-energy density, and high-power density lithium-ion batteries 69(9)1484-1496. https://doi.org/10. 1007/s11837-017-2404-9

Publisher's note Springer Nature remains neutral with regard to jurisdictional claims in published maps and institutional affiliations. 